\title{
Whole-Body Vibration Suppresses Gastric Motility in Healthy Men
}

\author{
Tatsuya ISHITAKE*, Mihoko KANO, Yuzo MIYAZAKI, Hideo ANDO, \\ Akizumi TSUTSUMI and Tsunetaka MATOBA \\ Department of Environmental Medicine, Kurume University School of Medicine, 67, Asahi-machi, Kurume 830- \\ 0011, Japan
}

Received November 7, 1997 amd accepted December 22, 1997

\begin{abstract}
The influence of whole-body vibration on gastric motility was investigated by using an electrogastrography (EGG) in seven healthy men. The EGG is usually referred to as a noninvasive technique of recording gastric myoelectrical activity by means of placing electrodes on the abdominal surface. Sinusoidal vertical vibration at each of 3 different frequencies $(10 \mathrm{~Hz}, 20 \mathrm{~Hz}, 40 \mathrm{~Hz})$ were randomly given to the subject seated on a platform of vibrator for $5 \mathrm{~min}$. The vibration magnitude was kept at a constant of $2.0 \mathrm{msec}^{-2}$ (r.m.s.) during operation. The mean dominant frequency of EGG at control period was prior to operation 3.3 cycles per min (cpm). During vibration exposure at $10 \mathrm{~Hz}$, the peak of dominant frequency increased to $3.9 \mathrm{cpm}$, and the relative power of slow wave showed the statistically significant decrease $(45.8 \%, p<0.05)$. The mean relative power of slow wave which is composed of frequencies ranged from 2.0 to $5.0 \mathrm{cpm}$ was $56.6 \%$ at control period. On the contrary the mean relative power of frequencies ranging from 5.0 to $9.0 \mathrm{cpm}$, tachygastria increased from $29.5 \%$ to $39.1 \%$. These results suggest that the short-term exposure to whole-body vibration effects on the gastric myoelectrical activity.
\end{abstract}

Key words: Electrogastrography (EGG), Gastric motility, Whole-body vibration

\section{Introduction}

According to several epidemiological studies, long-term whole-body vibration (WBV) exposure can be associated with a high prevalence of low-back pain ${ }^{1-3)}$. And also a high frequency of the gastrointestinal disorders has been observed among workers with WBV-exposure ${ }^{4,5)}$. However, there has been a big problem whether WBV is a specific risk factor against the gastric disorders such as gastric neurosis, gastric ulcer and duodenal ulcer. Few experimental studies have been reported concerning the human gastrointestinal responses to $\mathrm{WBV}^{6}$.

Cutaneous electrogastrography (EGG) is a potentially useful noninvasive technique for evaluating the gastric motility controlled by myoelectrical activity of the stomach ${ }^{7-10)}$. The

*To whom correspondence should be addressed. gastric slow motions are present at all the time, originating from the part of the corpus and propagating through the longitudinal muscle fiber to the pylorus. The human gastric signal composed of bradygastria $(0.5-2.0 \mathrm{cpm})$, slow wave $(2.0-5.0 \mathrm{cpm})$ and tachygastria $(5.0-9.0 \mathrm{cpm})^{11)}$. Gastric dysrhythmias except slow wave are believed to be associated with gastric dysmotility ${ }^{11)}$.

The aim of this study was to assess the short-term effect of whole-body vibration exposure on the gastric motility using by the cutaneous electrogastrography.

\section{Materials and Methods}

\section{Subjects}

Seven male medical students with a mean age of $24.5 \mathrm{yr}$ (range 22-28 yr) participated in this study. They had no history of disorders of the upper gastrointestinal tract motility. 
Smoking and taking coffee were prohibited for $6 \mathrm{hr}$ before the experiments. All subjects were carefully explained about this study prior to the study, and written consent forms were signed by each of them.

\section{Vibration exposure}

Subjects were asked to sit on the vibration platform without backrest in the comfortable posture. The vibration stimulus was produced by using an electromagnetic shaker (ASE385; AKASHI, Japan). The sinusoidal vibrations with three different frequencies, $10 \mathrm{~Hz}, 20 \mathrm{~Hz}$ and $40 \mathrm{~Hz}$, were randomly given to the subject for $5 \mathrm{~min}$. The magnitude of vibration was constantly kept at $2.0 \mathrm{msec}^{-2}$ (r.m.s.).

\section{Measurement of electrogastrography (EGG)}

The recording sites on the abdominal surface was lightly cleaned with ethanol and abraded with sandy skin paste to reduce skin-electrode motion artifacts. Two disposable AG/ $\mathrm{AgCl}$ electrodes (Vitrode, Nihon Kohden, Japan), $6 \mathrm{~cm}$ apart, were placed at the horizontal and one-fourth apart from the median between the xiphoid and the umbilicus. The EGG signals were amplified and filtered $(0.03$ to $0.2 \mathrm{~Hz})$ by a pre-amplifier (AB621-G, Nihon Kohden, Japan), and also digitized and stored simultaneously on the IBM computer with a sampling frequency of $2 \mathrm{~Hz}$.

\section{Experimental protocol}

To eliminate the effects of biorhythm and meal on the

EGG, each study commenced at about 5:00 in the afternoon. All subjects were asked nothing to eat and drink after an ordinary lunch. The mean fasting time was $4.5 \mathrm{hr}$. The subjects divided into two groups randomly were exposed to vibration in the order of 10,20 and $40 \mathrm{~Hz}$ in frequency for $5 \mathrm{~min}$. The one group took vibration with the abovementioned order and the other was exposed to vibration in the reversed order. The EGG data for 5 min were recorded before, during and after vibration exposure. During the operation, the noise level induced by the electromagnetic shaker was 72 to $74 \mathrm{~dB}(\mathrm{~A})$. The experimental room temperature was maintained at $22^{\circ} \mathrm{C}$ to $24^{\circ} \mathrm{C}$.

\section{Data analysis}

Frequency analysis of EGG was done using fast Fourier transform (FFT). Power spectrum was calculated every 5min-recording. Two EGG parameters were used for evaluation: 1) the mean dominant frequency of the EGG which may reflect the frequency of the slow wave, 2) the relative power changes of the slow wave $(2-5 \mathrm{cpm})$ and tachygastria $(5-9 \mathrm{cpm})$.

\section{Statistics}

The statistical evaluation of EGG was assessed by paired $\mathrm{t}$-test. Differences were considered to be significant at $\mathrm{p}<0.05$.

\section{Results}

Figure 1 indicates a typical waveform of EGG (A) and

(A)

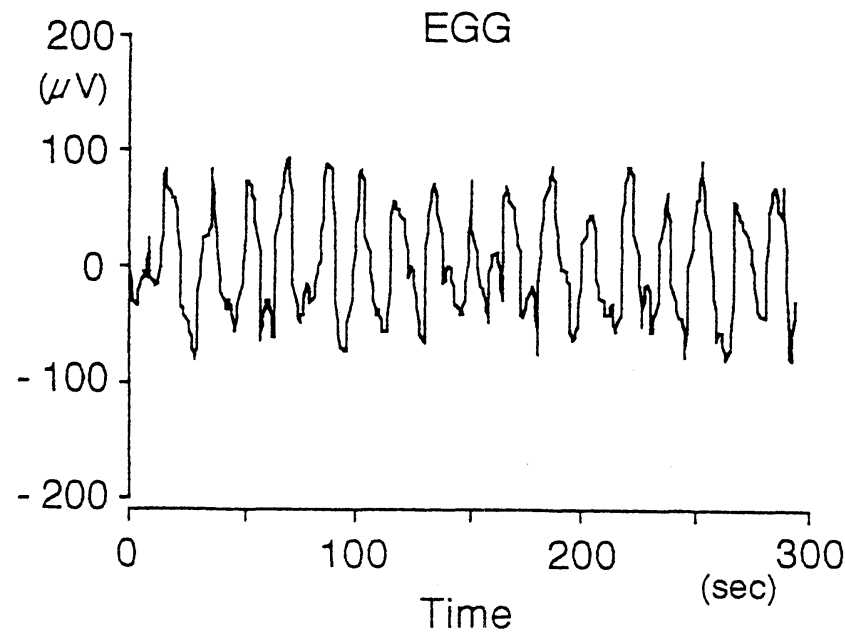

(B)

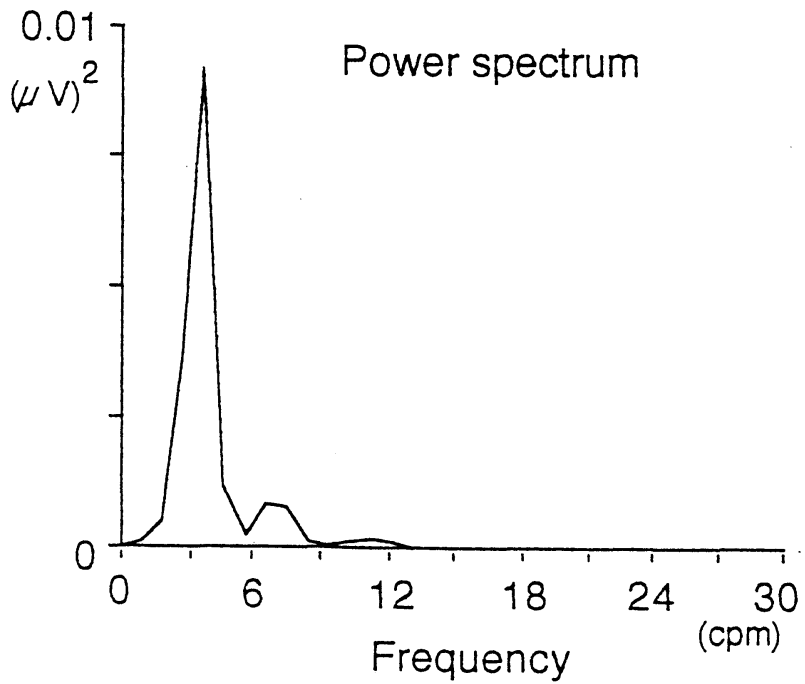

Fig. 1. Typical surface electrogastrogram (A) and its power spectrum (B) obtained in a healthy man under the condition of non-exposure of whole-body vibration 
its power spectrum (B) before vibration exposure. A regular and rhythmic EGG waveform was recognized. In the power spectral density, two peaks were observed. The big component was around $3 \mathrm{cpm}$ in frequency which we called the slow wave component, showing the dominant frequency of $3.7 \mathrm{cpm}$. The small and fast wave component was the frequency of 5 to $9 \mathrm{cpm}$. Six of 7 subjects $(86 \%)$ showed the slow wave component with frequency of 2 to $5 \mathrm{cpm}$. Typical changes of EGG waveform and its power spectra induced by whole-body vibration of $10 \mathrm{~Hz}$ in a subject are shown in Figure 2. The power of spectrum corresponding to the slow wave component was suppressed by vibration exposure. On the other hand, the power of fast wave component, tachygastria, increased relatively. When the vibration exposure finished, the composition of such components recovered to the previous constitution with slightly increased power.

The mean dominant frequency of EGG was $3.3 \mathrm{cpm}$ at control period, composing of $56.6 \%$ of slow wave and $29.5 \%$ of fast wave one (Table 1). The dominant frequency increased during vibration exposure except of $20 \mathrm{~Hz}$. However, these changes were not statistically significant. During vibration exposure of $10 \mathrm{~Hz}$, the slow wave decreased from $56.6 \%$ to $45.8 \%$ with a significant difference $(\mathrm{p}<0.05)$ and increased after vibration exposure $(\mathrm{p}<0.05)$. However, the relative power was scarcely changed under the condition of the exposure to the frequency of 20 and $40 \mathrm{~Hz}$. On the contrary the tachygastria $(5-9 \mathrm{cpm})$ at $10 \mathrm{~Hz}$ increased from $29.5 \%$ to $39.1 \%$ with a statistical significance $(0<0.05)$. At the other frequencies there were scarcely changes.

\section{Control}

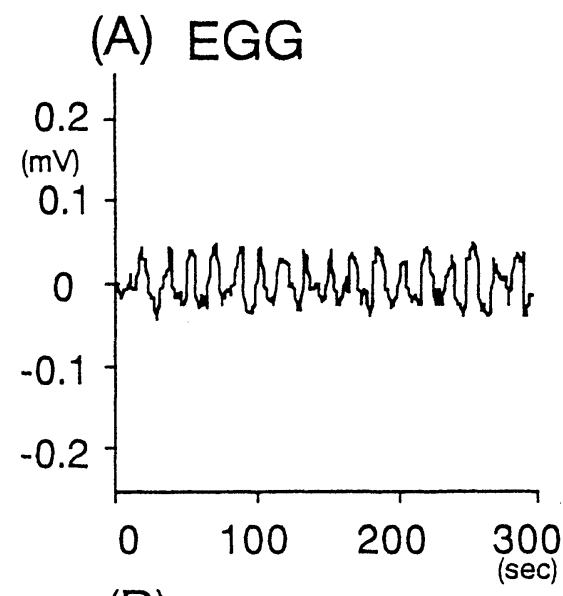

(B) Power spectra

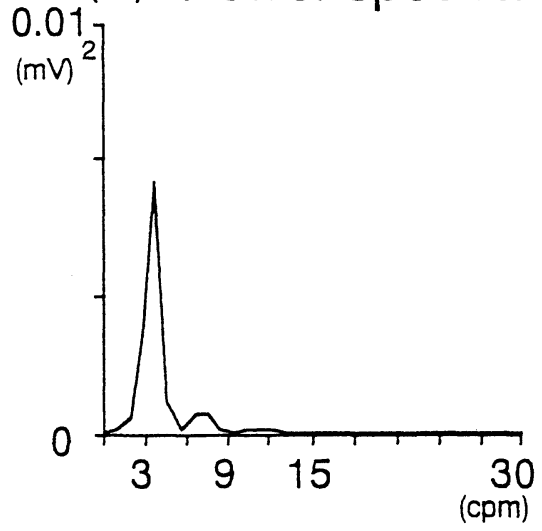

During
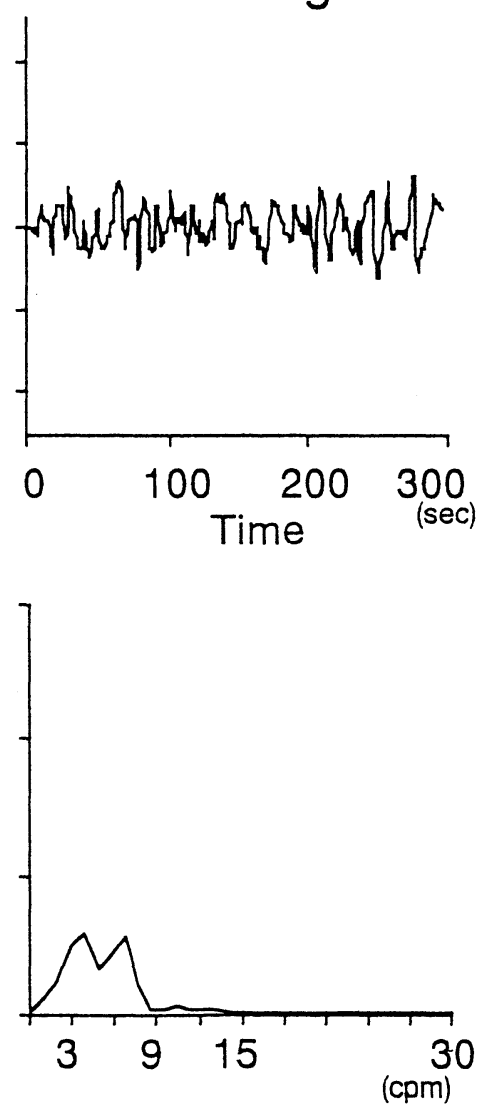

Vibration $(10 \mathrm{~Hz})$ After
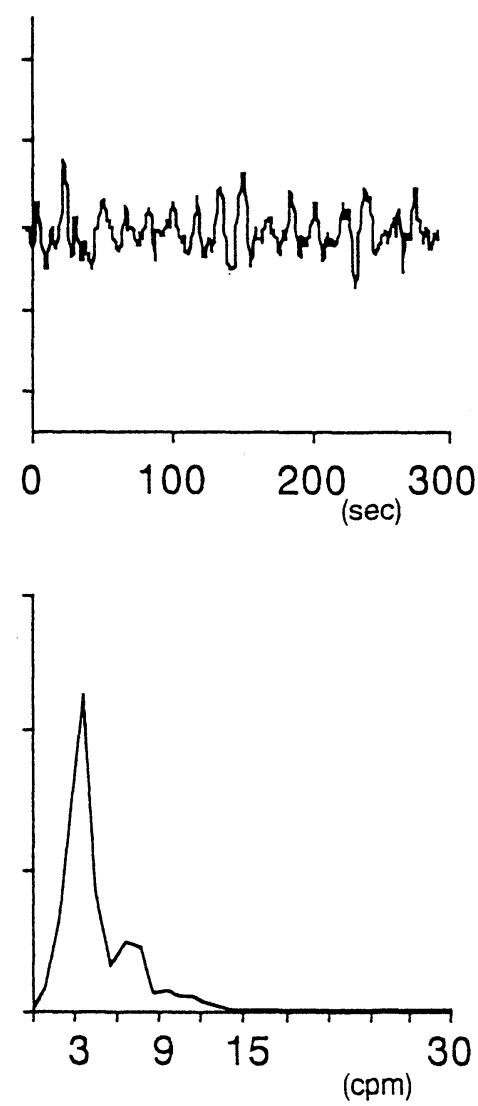

Frequency

Fig. 2. Effect of whole-body vibration of $10 \mathrm{~Hz}$ on electrogastrogram (A) and its power spectrum (B) in a healthy man 
Table 1. Effect of whole-body vibration exposure on EGG

\begin{tabular}{|c|c|c|c|c|c|c|c|}
\hline & \multirow{2}{*}{ Control } & \multicolumn{2}{|c|}{$10 \mathrm{~Hz}$} & \multicolumn{2}{|c|}{$20 \mathrm{~Hz}$} & \multicolumn{2}{|c|}{$40 \mathrm{~Hz}$} \\
\hline & & During & After & During & After & During & After \\
\hline $\begin{array}{l}\text { Dominant frequency } \\
\qquad(\mathrm{cpm})\end{array}$ & $\begin{array}{c}3.3 \\
(0.7)\end{array}$ & $\begin{array}{c}3.9 \\
(1.4)\end{array}$ & $\begin{array}{c}3.1 \\
(0.4)\end{array}$ & $\begin{array}{c}3.1 \\
(0.4)\end{array}$ & $\begin{array}{c}3.9 \\
(1.0)\end{array}$ & $\begin{array}{c}3.9 \\
(1.1)\end{array}$ & $\begin{array}{c}3.7 \\
(1.1)\end{array}$ \\
\hline \multicolumn{8}{|l|}{ Relative power (\%) } \\
\hline $\begin{array}{l}\text { Slow wave } \\
2-5 \mathrm{cpm}\end{array}$ & $\begin{array}{c}56.6 \\
(13.9)\end{array}$ & $\begin{array}{l}45.8 \\
(8.5)\end{array}$ & $\begin{array}{l}61.7 \\
(8.5)\end{array}$ & $\begin{array}{c}57.7 \\
(12.7)\end{array}$ & $\begin{array}{c}55.9 \\
(11.5)\end{array}$ & $\begin{array}{c}56.6 \\
(8.0)\end{array}$ & $\begin{array}{l}57.3 \\
(8.0)\end{array}$ \\
\hline Tachygastria & 29.5 & 39.1 & 25.7 & 31.4 & 31.5 & 28.9 & 29.0 \\
\hline $5-9 \mathrm{cpm}$ & (12.1) & (4.4) & $(3.5)$ & $(11.7)$ & (11.7) & (7.4) & $(8.9)$ \\
\hline
\end{tabular}

Mean (S.D.).

\section{Discussion}

Application of cutaneous EGG, noninvasive method has been limited until 1980s because of difficulty in data acquisition and interpreting EGG data ${ }^{11)}$. However, the information about the correlation between the EGG and gastric motility has been rapidly increased by the progression of computing supported technology. The validity of the cutaneous EGG is reliable for the measurement of the gastric slow wave ${ }^{12,13)}$. The dominant frequency of the EGG can accurately represents the frequency of the gastric motility. A relative increase of power spectral density may reflect to increase the contractile activity of the stomach. For concerning the gastric dysrhythmias, tachygastria, fast wave component $(5-9 \mathrm{cpm})$, was interpreted to be abnormal at nausea or vomiting ${ }^{7,9)}$.

The major result in our study was that the relative power spectral density of the slow wave $(2-5 \mathrm{cpm})$ decreased significantly as compared to the value of the control by 10 $\mathrm{Hz}$ of WBV. This findings suggest that short-term WBV exposure can suppress the gastric motility. In the evaluation of human responses to WBV, the resonance frequency should be considered because the biodynamic transmissions of vibration depend on this factor. In particular, the knowledge of the resonance frequency of the human body to WBV is the most important for evaluating the physiological and pathological reactions. According to the observation of the human by Dupuis and Zerlett ${ }^{14)}$, the internal organs movement increased at vibration frequencies of $3-5 \mathrm{~Hz}$ and $7-10 \mathrm{~Hz}$. They assumed that there was considerable strain in the tissues. These findings suggest that the passive gastric movement by vibration exposure may be maximum at $10 \mathrm{~Hz}$ comparing with exposure of 20 or $40 \mathrm{~Hz}$. However, the relationship between the gastric movement induced by WBV and the gastric motility in the EGG was still unkownn.

In case of more longer term of WBV exposure for $1 \mathrm{hr}$, Kjellberg and Wikström ${ }^{6)}$ observed a transient increase of relative power in the frequencies of $3,5.4$ and $7.8 \mathrm{cpm}$. They concluded that the gastric motility can be affected by WBV in certain frequency ranges. We observed an opposite response in the relative power of $3 \mathrm{cpm}$ in our unpublished data. This discrepancy may depend on the difference of vibration frequency, amplitude and duration of exposure. In addition, they carried out their experiments under the condition of no control of meal and fasting time. In our observation, food intake and fasting time were very important factors influencing the power spectral density of EGG. Some investigators have mentioned that taking a meal induces an increase of power in the slow wave (major frequency of about $3 \mathrm{cpm}$ ) in $\mathrm{EGG}^{12,15)}$.

Epidemiological study on long-term WBV exposure have revealed that high prevalence of gastrointestinal symptoms among occupations with WBV exposure have been reported ${ }^{4,5}$. However, definite evidence of dose-effect relationship and the mechanism of this impairments have not been clarified. In the patients with gastric neurosis and non-ulcer dyspepsia, decreased power of slow wave component after test meal was observed in EGG measurement ${ }^{7,11)}$. The acute effect of WBV on the gastric motility in this study would show the suppression of the contractile activity. This suppression may have probability of leading to the gastrointestinal disorder. In conclusion, short-term exposure to whole-body vibration can decrease contractile activity of the gastric motility.

\section{References}

1) Hulshof C, Van Zanten BV (1987) Whole-body vibration and low-back pain: A review of epidemiologic 
studies. Int Arch Occup Environ Health 59, 205-20.

2) Burdorf A, Zondervan H (1990) An epidemiological study of low-back pain in crane operators. Ergonomics 33, 981-7.

3) Bovenzi M, Zadini A (1992) Self-reported low back symptoms in urban bus drivers exposed to whole-body vibration. Spine 17, 1048-59.

4) Seidel H, Heide R (1986) Long-term effects of wholebody vibration: a critical survey of the literature. Int Arch Occup Environ Health 58, 1-26.

5) Miyashita $K$, Morioka I, Tanabe $T$, Iwata $H$, Takeda $S$ (1992) Symptoms of construction workers exposed to whole body vibration and local vibration. Int Arch Occup Environ Health 64, 347-51.

6) Kjellberg A, Wikström BO (1987) Acute effects of whole-body vibration: Stabilography and electrogastrography. Scand J Work Environ Health 13, 243-6.

7) Geldof H, Van der Schee EJ, Van Blankenstein M, Grashuis JL (1987) Electrogastrographic study of gastric myoelectrical activity in patients with unexplained nausea and vomiting. Gut 27, 799-808.

8) Pfister CJ, Hamilton JW, Nagel N, Bass P, Webster JG, Tompkins WJ (1988) Use of spectral analysis in the detection of frequency differences in the electrogastrograms of normal and diabetic subjects. IEEE Trans Bio Eng 35, 935-41.

9) Chen J, Yeaton P, McCallum RW (1992) Effect of erythromycin on gastric myoelectrical activity in normal human subjects. Am J Physiol 263, G24-8.

10) Smout A, Van der Schee EJ, Grashuis JL (1980) What is measured in electrogastrography? Dig Dis Sci 25, 179-87.

11) Chen J, McCallum RW (1993) Clinical applications of electrogastrography. Am J Gastroenterol 88, 1324 36.

12) Chen J, Richards RD, McCallum RW (1994) Identification of gastric contractions from the cutaneous electrogastrogram. Am J Gastroenterol 89, 79-85.

13) Sun WM, Smout A, Malbert $C$, Edelbroek MAL, Jones K, Dent J, Horowitz M (1995) Relationship between surface electrogastrography and antropyloric pressures. Am J Physiol 268, G424-30.

14) Dupuis H, Zerlett G (1986) The effects of whole-body vibration. 39-44, Springer-Verlag, Berlin.

15) Chen J, McCallum RW (1991) Response of the electric activity in the human stomach to water and a solid meal. Med Biol Eng Comput 29, 351-7. 